\title{
InTERLÚdio PARA PAOLONCELO: Paul Celan em Bucareste
}

\author{
Interlude for PaOloncello: \\ Paul CELAN in BuCAREST
}

Jan H. Mysjkin

Bucareste, Romênia

Paris, França

Palavras-chave: Paul Celan; literatura romena; Surrealismo.

Keywords: Paul Celan; Romanian literature; Surrealism. Mots clés: Paul Celan; Littérature roumaine; Surréalisme.

\section{Resumo}

Paul Celan é reconhecido internacionalmente como um poeta que marcou a literatura alemã do século XX. Sabe-se menos que ele nasceu na Romênia e fez suas primeiras publicaçóes em romeno. $\mathrm{O}$ artigo retraça os anos de Paul Celan em Bucareste, escrevendo, traduzindo e publicando em romeno.

\begin{abstract}
Paul Celan is internationally renowned as an influential poet in 20th century German literature. It is less known, however, that he was born in Romania and debuted in Romanian. The article retraces Paul Celan's steps when he lived in Bucharest, writing, translating and publishing in Romanian.
\end{abstract}

\begin{abstract}
Résumé
Paul Celan est mondialement reconnu en tant que poète qui a marqué la littérature allemande du vingtième siècle. Il est moins connu qu'il est né en Roumanie et qu'il a fait ses débuts en roumain. L'article retrace les années que Paul Celan a vécues à Bucarest, écrivant, traduisant et publiant en roumain.
\end{abstract}

Fim de abril de 1945, Paul Antschel foge de Cernauti, sua cidade natal, para Bucareste, com alguns livros, um monte de manuscritos e um punhado de dinheiro como única bagagem. Era a passagem da "Pequena Viena" para a "Pequena Paris", como essas duas cidades eram chamadas no período entreguerras. Cernauti era a capital da Bucovina, uma regiáo atribuída à Romênia, quando a dupla monarquia austro-húngara se desintegrou, ao final da Primeira Guerra Mundial. Paul Antschel nasceu nessa cidade em 23 de novembro de 1920. Nessa época, metade dos cem mil habitantes era de judeus, e falava-se uma mistura de línguas, dentre as quais o alto alemão, o ídiche, o ucraniano, o romeno e o suábio, isso sem mencionarmos os dialetos. Em casa, Paul Antschel foi educado em 
alemão e na escola sua formação deu-se em romeno. Em junho de 1940, na ocasiáo do pacto Molotov-Ribbentrop, as tropas russas violavam a integridade da Romênia neutra e ocupavam o norte da Bucovina. Pouco depois, a Romênia entrava em guerra ao lado das forças do Eixo. Ao final da Segunda Guerra Mundial, a regiáo foi definitivamente anexada à União Soviética. Como os soviéticos se comportaram de maneira ainda mais dura e arbitrária do que os nazistas com relação ao povo - acusando os judeus (germanófonos) de colaboração com os alemães! -, Paul Antschel, embora marxista convicto, escolheu o caminho do exílio.

Ao chegar a uma cidade que se recuperava após a guerra, o refugiado de vinte e quatro anos encontrou rapidamente um emprego como revisor na editora Cartea Rusa (O Livro Russo), onde fez resenhas de manuscritos e traduziu textos do russo para o romeno. Assim, os primeiros livros publicados por Paul Antschel foram traduçôes, dentre as quais: Os camponeses, um conto de Tchekhov, A questão russa, uma peça de teatro de Simonov, e Herói do nosso tempo, um romance de Lérmontov. Ele assinava esses trabalhos com os pseudônimos Paul Aurel, A. Pavel e Paul Ancel, mas estas não foram suas primeiras investidas na tradução: na Bucovina, ele já havia traduzido para o romeno textos de Karl Marx, publicados em uma revista estudantil, e também manteve vínculo como tradutor com um jornal ucraniano.

Através de seu trabalho na editora, Paul Antschel entrou automaticamente em contato com o mundo literário romeno. A grande figura da redação da Cartea Rusa era Alexandru Philippide (1900-1979), um poeta eminente e tradutor erudito, que fazia da reuniấo semanal um verdadeiro banquete intelectual. No outono de 1946, a redação foi reforçada com a presença de Petre Solomon (1923-1991), um poeta da mesma idade que Celan e que se tornaria um amigo para toda a vida. Foi graças a Solomon que os poemas romenos de Celan chegaram até nós, infelizmente não todos, e nem sempre completos. Além disso, na posição de testemunha ocular privilegiada, Solomon registrou os anos de Celan em Bucareste no seu estudo Paul Celan. Dimensiunea romanească (Paul Celan. A dimensão romena, 1987).

Nele, Solomon descreve os anos imediatamente após a guerra como uma época relativamente feliz, inclusive para Antschel, cujos pais haviam perecido nos campos de trabalho nazistas. O perfil que ele traça de seu antigo colega nos mostra "um jovem rapaz inventivo 
e jovial, de cabelos castanhos e olhos marrom claro, elegante em seus movimentos e distinto em sua atitude". Suas feridas de guerra pareciam curadas, ao menos ele náo falava na frente dos colegas e dos amigos nem da morte dos pais, nem do trauma associado a ela. O trabalho na editora era bem remunerado, de maneira que os dois rapazes podiam participar plenamente da vida cultural da capital romena. Além disso, Solomon descreve seu amigo como um "notívago" que se entretinha até o nascer do sol escrevendo poemas, passeando com alguma namorada ou conversando com amigos.

Festas também não faltavam, especialmente no apartamento de Nina Cassian (1924), que era totalmente envolvida tanto com a pintura quanto com a música e a poesia. "Paul se sentia bem à vontade entre as paredes cobertas por quadros daquele apartamento confortável onde um robusto piano 'Bechstein' ocupava um lugar de honra," conta Solomon. "Nina presidia nossas 'noites musicais e literárias', que não deixavam nada a desejar com relação a certos círculos outrora famosos em Bucareste. Jogávamos sempre jogos surrealistas como 'perguntas e respostas' ou 'Joachim', a variante de Bucareste para o 'cadáver delicado' que Breton e seus amigos elevaram à perfeição nos anos após a Primeira Guerra Mundial. Do apartamento ecoavam cançóes, tanto inocentes quanto libertinas. Paul emprestava sua voz grave e trêmula àquelas noites musicais, cantando ora em coro, ora sozinho. Seu repertório rico e variado era composto por cançóes revolucionárias da Guerra Civil Espanhola e canções alemãs da Idade Média, dotadas de uma estranha beleza."

Um frequentador desses encontros no salão de Nina Cassian era o futuro romancista Marin Preda (1922-1980), da mesma geração de Celan e Solomon. Quando, três décadas mais tarde, ele quis incluir em seu romance Delirul (A loucura, 1975), uma cena em que os personagens jogavam o "jogo de perguntas e respostas", ele foi refrescar a memória com Solomon. As perguntas e respostas que Celan e Solomon tinham anotado na época foram quase todas inseridas praticamente intactas no romance de Preda. Cito, para registrar a cor local, a passagem em questão:

"O que vamos jogar agora?" perguntou Luchi. "Joachim ou Perguntas e respostas?"

"Primeiro Joachim", gritou Adrian.

"Ah não, para relaxar é melhor Perguntas e respostas", disse o Dr. Spurcaciu, que, para a estupefação de Stefan, subitamente queria se divertir. 
"Quem faz as perguntas?", perguntou Luchi.

"Eu", disse Sebi, inclinando quase imperceptivelmente o lado da cabeça do qual ele não ouvia nada.

"Ah não", gritou sua namorada. "Sou eu que faço as perguntas."

Bom, todo mundo estava de acordo.

"Esperem, vocês todos conhecem o jogo?", disse Luchi.

"Stefan, você vai entender rápido, as perguntas são espontâneas e as respostas também. É proibido refletir. Vai lá, Cora.”

"O que é a solidão do poeta?", perguntou ela com uma voz cuja sinceridade não simulada repentinamente agradou a Stefan.

"Um número de circo que não está no programa", gritou o Dr. Spurcaciu numa só tacada.

Vejam só... Ele debochava dos poetas... Um número de circo... Hum!

"O que é uma lágrima?", retomou rapidamente a jovem.

"Uma balança à espera dos pesos”, disse Adrian após um momento de hesitação geral.

O que quer dizer isso? Será que as lágrimas só têm sentido se tiverem sido pesadas? Ou seráo elas apenas o fundo da dor, só recebendo peso por seus sentidos?

"O que é a embriaguez?", retomou a jovem.

Silêncio. Nota-se que eles hesitam diante de uma coisa tão banal.

"Uma folha branca no meio de outras coloridas", disse enfim Sebi.

"Simbólico demais", gritou alguém, "fraco..."

"Ah não, muito bem... A embriaguez é o esquecimento, como uma folha branca, excelente...”

"O que é o esquecimento?", perguntou a poetisa, tendo acabado de ouvir essa palavra.

"Uma maçã que ainda não está madura cravada por uma lança", disse Lazarovici, e as exclamaçôes se multiplicaram: formidável... De onde você tira tão rápido uma resposta tão sugestiva?

"O que é o retorno?", retomou a poetisa com sua sinceridade apaixonada.

"Quase nada", diz Niki, "mas poderia ser um floco de neve."

Bravo! Bonito! O retorno é um inverno que chega! Bravo, Niki!

"O que é a última noite antes da partida?"

Stefan se precipitou. Ele queria ter respondido a essa pergunta, mas nada lhe vinha à cabeça. Ele havia compreendido o jogo: era preciso uma metáfora cifrada, mas ao mesmo tempo tão verdadeira quanto expressiva.

"O que é um ano novo?", continuou a poetisa, desistindo da resposta anterior.

"Uma história de amor que se encerra."

Fraco, mesmo que a comparação entre um ano e a mulher amada não fosse assim tão ruim...

"O que é uma tristeza?"

"Um caminho que se preenche antes de alcançar a margem do rio", disse Dr. Spurcaciu, provocando gritos de admiraçáo. 
Como ele teve essa ideia? Doutor, o senhor se torna suspeito depois de ter fatiado tantas pessoas no hospital: ou o senhor lê poesia hermética, ou...

"O que é um réveillon?"

Stefan, que acabava de esvaziar o copo, se pegou respondendo: "Um copo de vinho no qual se colocou veneno."

Hum! Por que veneno? Porque sim! De qualquer forma, tinha sido bem espontâneo...

"O que é a mulher amada?", perguntou de repente Cora Petrasincu, com uma voz alterada.

E aí chegamos! Muito bem, o que era a mulher amada? Os momentos passavam e a pergunta perigava de ficar sem resposta.

"É a última pergunta," anunciou a poetisa. "Vocês podem pensar em outras respostas..."

Evidentemente, ninguém podia encontrar uma resposta inteiramente correta; por outro lado, não teria sido engraçado, pois era sempre necessário um gancho com algum jogo de palavras, que na realidade não exprimia nada.

"Um lenço ainda em movimento", disse alguém.

"O triste despertar após uma noite sem constelaçôes”, disse outra pessoa. E assim continuou.

Todos se declararam satisfeitos, pararam de jogar e passaram ao jogo seguinte. ${ }^{1}$

Outro contato importante era Margul Alfred-Sperber (18981967). Nascido na Bucovina, na época em que a regiâo era parte integrante da coroa austríaca, Margul Alfred-Sperber serviu no exército austro-húngaro durante a Primeira Guerra Mundial. Após uma vida de boemia em Paris e Nova Iorque, ele retornou ao país natal, onde havia construído um nome como poeta e homem de letras. Em Viena, tinha frequentado os expressionistas, em Praga, tinha conhecido Franz Kafka, e mantinha uma correspondência com T.S. Eliot. Responsável pela página literária do Czernowitzer Morgenblatt, tinha oferecido a vários autores iniciantes a possibilidade de publicar. Embora tenha se estabelecido em Bucareste em 1940, Margul-Sperber permanecia como um ponto de referência para a jovem geração germanófona na Bucovina; foi assim com Paul Antschel, que, antes de sua vinda a Bucareste, tinha endereçado a Margul-Sperber um manuscrito de poemas. Ele ficou maravilhado com o material proposto, ao ponto de usar toda a sua influência para publicar o poeta desconhecido. Antschel, Cassian e Solomon

\footnotetext{
${ }^{1}$ As citaçóes de textos do artigo original foram traduzidas do romeno pelo autor do artigo. As traduçóes para o português foram feitas a partir dessas traduçôes. (N. do T.)
} 
eram frequentadores da casa de Margul-Sperber, que acolhia todos os domingos amigos e poetas em seu salão. No decorrer de uma dessas visitas, foi escolhido o nome de um autor que náo desaparecerá tão cedo da enciclopédia da literatura mundial. Cito o relato do episódio feito por Solomon:

Ao "marinar" com Margul-Sperber seu futuro poético, Paul achava que seu sobrenome, Antschel - um nome absolutamente comum na Bucovina -, não tinha poder mágico suficiente. A discussão inflamada acerca dessa questão fora interrompida pela esposa de Sperber, Ietty, que sugeriu o pseudônimo de "Celan", anagrama de seu nome escrito segundo a ortografia romena, "Ancel”, com o qual ele já havia assinado algumas traduçóes e artigos.

Na verdade, esse nome é o resultado de um jogo de palavras e de sons que, na época, era uma prática comum em Bucareste. Mais tarde, Celan designou esses anos passados em francês como "a bela temporada dos trocadilhos". Encontravam-se jogos de palavras por toda parte: nos jornais, nos letreiros, nas conversas. Segundo o testemunho de Solomon, Celan era uma verdadeira fonte de boas frases e de aforismos, dentre os quais uma boa quantidade foi transcrita em um caderno. Essas anotaçóes estão todas em romeno, às vezes, com alguns correspondentes franceses. Por exemplo: "In poezie nu se assteaptă tonul cind se telefonează" - "En poésie, on n'attend pas la tonalité pour téléphoner" ("Em poesia, não se espera dar linha para telefonar"). A deformação de nomes próprios constituindo um jogo de sons, Margareta era transformado em Gargareta; sua amizade com Petre era caracterizada com um "solo de Petronom, cu acompaniament de Paoloncel" - "solo pour Petronome, avec accompagnement de Paoloncelle" ("solo para Petrônomo, com acompanhamento de Paoloncelo"); quando Aderca, um colega na editora, era chamado ao telefone, ele gritava "Alafon la Telederca". O anagrama de "Ancel" em "Celan" se encaixa perfeitamente nessa atmosfera lúdica. Entretanto, esses jogos de palavras não me parecem todos tão inocentes, por exemplo, quando ele se define como "Paul Celan: persona gratata", fazendo-nos ouvir não somente o "persona (non) grata" do latim, mas sobretudo a "persoană gratiată" ("pessoa agraciada") do romeno.

Após as privações da guerra, o jogo fervente com as palavras e os sons exprimiam uma alegria reencontrada da vida. Esse jogo era também característico do surrealismo, cuja variante romena encontrou seu apogeu em Bucareste precisamente entre 1945 e 
1947. Graças aos contatos com os escritores e pintores exilados em Paris, como Tristan Tzara ou Victor Brauner, os romenos estiveram bem informados sobre o surrealismo no período entreguerras. Entretanto, um verdadeiro grupo surrealista aparece somente em 1939, quando os jovens poetas Gherasim Luca (1913-1994) e Gellu Naum (1915-2001) retornam de Paris, onde fizeram seu aprendizado junto a André Breton e Benjamin Peret. Infelizmente, a tomada do poder pelos fascistas interrompeu-lhes o impulso, antes mesmo de eles terem a chance de decolar. $\mathrm{Na}$ época da Liberação, nada mais pôde retê-los. $\mathrm{O}$ grupo surrealista, composto também agora por Virgil Teodorecsu, Paul Păun e Dolfi Trost, publica livros em sequência, lança manifestos atrás de manifestos, organiza exposiçóes uma após a outra. Paul Celan, que tinha tomado conhecimento do movimento na ocasiáo de sua estadia na França, durante seus estudos de medicina em 1938, é contagiado pela euforia surrealista após uma visita à Expoziţie Suprarealistă, no outono de 1946.

Celan nunca foi membro de um grupo surrealista, mas gostava de se juntar a eles nos momentos de leituras e de festas, sempre mantendo certa distância, pois era o único poeta germanófono em um ambiente romeno. Ele se sentia mais particularmente atraído pelo círculo em torno de Gherasim Luca; entretanto, uma relação mais próxima só foi se concretizar tempos depois, quando eles se reencontraram na condiçâo de exilados, em Paris. O interesse de Celan pelo surrealismo não se limitava ao aspecto lúdico, como o "jogo das perguntas e respostas" ou o "joachim" mencionados anteriormente, que sempre eram jogados em romeno. Ele também era fascinado pelas técnicas através das quais o inconsciente e o sonho eram revelados e registrados. Assim, não é de se estranhar que Celan tenha se dedicado à escrita automática e ao ditado do sonho em romeno, e não em alemão.

O entusiasmo com o qual seus poemas em alemão foram recebidos por seus amigos romenos foi com certeza um estímulo a mais. Petre Solomon havia traduzido um deles, e o jovem crítico Ovid S. Crohmălniceanu (1921-2000) - mais um apaixonado pelas noites na casa de Nina Cassian - levou-o para a revista Contemporanul (O contemporâneo). Foi aí que, em 2 de maio de 1947, apareceu pela primeira vez um poema sob o nome de Paul Celan, a saber "Tangoul mortii" ("O tango da morte"), que se tornaria famoso com o título "Todesfuge" ("Fuga da morte"). A relação cotidiana com o romeno enquanto redator e tradutor, a recepção favorável de suas traduçóes 
e de seus poemas no mundo literário de Bucareste, os incentivos de seus amigos, a atividade frenética do surrealismo, tudo isso certamente contribuiu para a passagem de Celan ao uso criador do romeno. Desses anos em Bucareste, chegaram a nós dezesseis poemas em romeno: oito poemas em verso e oito poemas em prosa.

A literatura romena já tinha deixado traços na obra em alemáo de Paul Celan, por exemplo a "doină", cançâo popular elegíaca, na qual a natureza é vista como testemunha de um sofrimento pessoal. Essa forma é retomada por Celan no poema "Espenbaum" ("Álamo") de 1945, por exemplo, para dizer a morte de sua mãe. Além disso, Celan era um grande admirador da obra do poeta romeno Tudor Arghezi (1880-1967), a tal ponto que tinha especulado sobre a possibilidade de traduzir todos os seus poemas em alemão.

Nos anos de 1946-1947, Celan dá um passo a mais; ele não só incorpora elementos romenos ao alemáo como começa a escrever diretamente em romeno. Segundo a tese de Solomon, esse passo foi decisivo na evolução de Celan:

Em alemão, ele se sentia prisioneiro de certos clichês prosódicos e estilísticos dos quais queria se livrar. Uma passada de olhos nos poemas do período de Cernauti é suficiente para notar que certos leitmotiven e símbolos de origem livresca contrariam o resultado, mesmo que carregados da experiência pessoal do poeta. Muitos poemas do começo são rigorosamente metrificados e rimados. Acho que Paul Celan encontrou seu próprio ritmo em Bucareste - talvez ele também o tivesse encontrado em outro lugar, mas o fato é que ele o encontrou e experimentou aqui, tanto em romeno quanto em alemão. Uma das explicaçóes possíveis para isso, a meu ver, é o contato vivo do poeta com as práticas surrealistas.

Contrariamente ao alemão, o romeno era também uma língua "não contaminada". Mais de uma vez, perguntou-se a Celan como ele podia escrever na língua daqueles que tinham assassinado seus pais, e ele respondia: "Nur in der Muttersprache kann man die eigene Wahrheit aussagen, in der Fremdsprache lugt der Dichter" "“Só podemos expressar nossa própria verdade em nossa língua materna, em língua estrangeira, o poeta mente"). Em sua generalidade, esse julgamento é errôneo - basta pensar em seus compatriotas Emil Cioran, Eugen Ionescu, Panait Istrati, Gherasim Luca ou Tristan Tzara, que adquiriram todos um renome mundial como escritores franceses. Também, seus próprios poemas em romeno não perdem em nada para os poemas em alemão do mesmo período, reunidos mais tarde na antologia Der Sand aus den Urnen (A areia das 
urnas, 1948). Tanto do ponto de vista prosódico quanto temático, é interessante colocá-los lado a lado. O exemplo mais tocante é o "Poema para a sombra de Mariana" e seu homólogo alemão, "Marianne". Nota-se que os poemas romenos revelam uma liberdade nas relaçóes com a língua que ele não havia mostrado anteriormente em alemão, mas que conservou para a sequência em sua língua materna; somente "Tristeza” fica na mesma prisão incômoda dos poemas trazidos de Cernauti.

Os poemas em prosa, em especial, adquirem um lugar particular na obra de Celan, e não possuem equivalentes em alemão, com exceção de Gesprach im Gebirg (Conversa nas montanhas, 1959). Quanto à cronologia, é interessante notar que Paul Celan "colocou" ("a déposé") seu pseudônimo pela primeira vez no poema “PARTIDÁRIO DO ABSOLUTISMO ERÓTICO...”, datado de 11 de março de 1947:

PARTIDÁRIO DO ABSOLUTISMO ERÓTICO, megalomaníaco reticente mesmo entre os escafandristas, e além disso mensageiro do halo de Paul Celan, eu só evoco os traços petrificantes do dirigível naufragado a cada dez anos (ou mais), e só patino em um hora bem tardia sobre um lago, guardado por todos os lados pela gigantesca floresta dos membros acéfalos da Conspiração Poética Universal. É fácil compreender que aqui não se penetra com as flechas do fogo visível. Na extremidade do mundo, uma vasta cortina de ametista dissimula a existência dessa vegetação antropomórfica, além da qual eu tento selenicamente uma dança que me deixaria estupefato. Até o momento, ainda não consegui, e com meus olhos voltados para minhas têmporas, olho-me de perfil, esperando a primavera.

Livre das restriçóes prosódicas e com o modelo dos surrealistas sob os olhos, Celan se permite nessa prosa lírica uma proliferação mais ampla de imagens e uma desarticulação sintática mais audaciosa do que em qualquer outro texto do mesmo período. Não somente o surrealismo o impulsionou em romeno a uma ousadia sem precedentes no plano da língua, como também o levou, no plano temático, a expressar experiências que ele jamais havia verbalizado anteriormente em alemão, e para as quais ele não retornará mais no futuro. Penso particularmente no poema "Como o dia seguinte...”, o único no qual Celan escreveu sobre as deportações nazistas em Cernauti.

Em meados de 1947, a situação política na Romênia era cada vez mais ameaçadora, pela iminência da tomada de poder pelos comunistas. Com os surrealistas judeus Luca, Paun e Trost, Celan 
preparava uma fuga em conjunto do país. Finalmente, com a usurpação do poder pelos stalinistas, Paul Celan foge sozinho no início de dezembro de 1947, e com toda a pressa, da Pequena Paris para a Grande Viena. Ele náo tinha documento de identidade; sua bagagem se limitava a uma mochila com alguns manuscritos; o pouco dinheiro que tinha foi para os bolsos de um contrabandista, que o fez atravessar clandestinamente a fronteira com a Hungria. Viena, a cidade dos seus sonhos de juventude, revelou ser um pesadelo, tanto que seis meses mais tarde Celan prosseguiu em sua fuga rumando para a Grande Paris (de onde fugiria para a morte, em 20 de abril de 1970).

Qual teria sido o destino literário de Paul Celan se ele não tivesse sido obrigado a fugir de Bucareste? Todas as traduçóes de seus anos em Bucareste têm o romeno como língua alvo. Se nos basearmos no material reunido em Das Fruhwerk (1989), a produção poética é de 26 poemas em alemão e 16 poemas em romeno, em uma relação de três para dois. Não há razão a priori para acreditar que essa relação teria sido diferente se ele tivesse ficado na Romênia. Entretanto, para além das fronteiras romenas, não havia mais nenhuma razão para continuar sua prática criativa da língua romena. Já mencionei Cioran, Ionesco e Luca, que abandonaram o romeno para dar início a uma carreira brilhante em francês. Eles não poderiam ter sobrevivido como escritores se tivessem continuado a praticar o romeno: de um lado, as possibilidades de publicação no país de origem estavam extintas, de outro, a diáspora romena não oferecia nenhuma base viável. Reconverter-se à língua da terra que os acolhera era a única estratégia de sobrevivência possível. Entretanto, a situação de Celan não é inteiramente comparável à de seus compatriotas citados: Celan começou como poeta germanófono, em seguida retornou à língua alemã como única língua de expressão poética após o interlúdio bilíngue em Bucareste. Em consequência disso, os poemas de Celan em romeno adquiriram erroneamente o caráter de uma saída para uma outra língua. No âmbito das letras romenas, os poemas de Celan integram no mais alto nível a vanguarda da época. No âmbito de sua obra, eles refinam e completam a imagem que se pode fazer dele enquanto leitor e pesquisador - pois Celan permanece Celan, também em romeno. 
Jan H. Mysjkin é um escritor e tradutor belga, e vive em Paris e Bucareste. Este ano publicou Etc., etc ..., seu oitavo livro de poemas. Em 2012 foi premiado com o Prêmio Jaffé Elly pela primeira tradução completa para o holandês de $O$ Conde de Montecristo, de Alexandre Dumas. Sua poesia foi traduzida para mais de 40 idiomas. E-mail: <janmysjkin@hotmail.com> 